\title{
Composite vein grafting: Is it a "Y's" decision?
}

\author{
Saswata Deb, MD, ${ }^{\mathrm{a}, \mathrm{b}}$ Domingos S. R. Souza, MD, ${ }^{\mathrm{c}}$ and Stephen E. Fremes, MD ${ }^{\mathrm{a}, \mathrm{b}}$
}

See related article on pages 487-93.

Composite grafting techniques from the in situ left internal thoracic artery (LITA) has many theoretic advantages, which include a reduction in stroke by minimizing aortic manipulation along with greater utilization of available conduits. ${ }^{1}$ Although this technique has become popular with multiarterial grafting, ${ }^{2}$ arteriovenous composites are less accepted because of poor patency and flow dynamics. ${ }^{3}$ Excellent results have been reported in a recently published randomized trial, however, which showed that the saphenous vein grafts (SVGs) harvested with a minimal manipulation no-touch technique were not inferior to the right internal thoracic arteries as Y-grafts off the LITA with respect to 1-year angiography (SAVE RITA). ${ }^{4}$ In this issue of the Journal, the same group has published an observational study to provide potential mechanistic reasons for the trial findings. ${ }^{5}$

More specifically, Hwang and colleagues ${ }^{5}$ have published their single-institution cohort of 28 patients who underwent off-pump coronary artery bypass grafting surgery (CABG) with the no-touch SVG harvesting technique; as in the trial, these were constructed as composite Y-grafts from the in situ LITA. They performed quantitative angiography immediately after CABG and at 1 year; intravascular ultrasonography was only performed at 1 year for ethical reasons. Their main findings were that mean luminal diameter was decreased in SVGs at 1 year, whereas it was increased in the proximal portion of the LITA and remained unchanged in the distal portion of the LITA. Furthermore, the proportion of intimomedial area and ratio of intimomedial thickness to vessel diameter were similar between vein grafts and LITA at 1 year. These results collectively suggest appropriate SVG negative remodeling.

The main strengths of this study are the objective markers of graft disease through quantitative angiography and

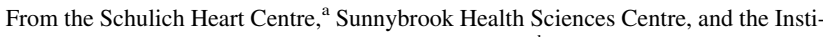
tute of Health Policy Management and Evaluation, ${ }^{\mathrm{b}}$ University of Toronto, Toronto, Ontario, Canada; and the Department of Thoracic and Cardiovascular Surgery, ${ }^{\mathrm{c}}$ Orebro University Hospital, Orebro, Sweden.

Disclosures: Authors have nothing to disclose with regard to commercial support.

Received for publication Nov 16, 2014; accepted for publication Nov 17, 2014.

Address for reprints: Stephen E. Fremes, MD, Bernard S. Goldman Chair in Cardiovascular Surgery, Schulich Heart Centre, Sunnybrook Health Sciences Centre, University of Toronto, 2075 Bayview Ave, Room H405, Toronto, ON M4N 3M5,

Canada (E-mail: stephen.fremes@sunnybrook.ca).

J Thorac Cardiovasc Surg 2015;149:494-5

$0022-5223 / \$ 36.00$

Copyright (c) 2015 by The American Association for Thoracic Surgery

http://dx.doi.org/10.1016/j.jtcvs.2014.11.046
}

intravascular ultrasonography. More specifically, patients underwent invasive angiography at a mean of 1.2 days and 12.9 months after surgery, which provides insight into both absolute and relative changes in luminal properties during an important period. Another strength of this study is that it is the first study to assess composite venous Y-grafts with intravascular ultrasonography. Furthermore, this unique study incorporates pertinent aspects of biology, physics, and clinical medicine.

There are a number of points worth discussing. First, this is a small observational study, and any findings are therefore hypothesis generating. The increase in diameter of the proximal LITA and decrease in diameter of the venous grafts suggest that the internal thoracic artery can successfully remodel to accommodate the flow of the entire left ventricular myocardium; meanwhile, the minimally manipulated healthy vein successfully remodels by decreasing in size on the basis of flow demand. This could explain the greater reduction in luminal size in grafts supplying single distals relative to multiple distals in this study. Furthermore, factors such as surgical decision making, patient selection, details of target runoffs, and the order in which the sequentials are placed (ie, placing the most distal sequential [or not] on the target with the greatest runoff) ${ }^{6}$ are important but can be cumbersome to capture quantitatively in a study. The multivariate analysis in this study would have been more robust if it had included such factors along with size and severity of proximal stenosis of target vessel.

Although composite grafting does have several theoretic advantages, there are also a few caveats, including competitive flow and steal. Sabik and coworkers ${ }^{7}$ demonstrated a decrease in internal thoracic artery patency as competitive flow increases; given that the major benefit of CABG is dependent on a patent LITA graft to the left anterior descending coronary artery territory, composite grafts to other territories from the LITA should be performed with caution. Another potential problem involving the LITA after CABG is the development of coronary subclavian steal syndrome, which occurs in as many as $3.4 \%$ of patients. ${ }^{8}$ There is also a potential for steal from the LITA that can occur when large, high-caliber vessels such as the SVG are anastomosed as a proximal LITA composite ${ }^{3}$; perhaps avoidance of manual dilation of the distal vein before anastomosis can potentially decrease this risk. Problems with steal become magnified when the LITA is the only source of inflow, which can jeopardize a large revascularized territory of the heart.

Overall, Hwang and colleagues 5 should be congratulated for this unique study providing objective measures of graft 
wall characteristics according to harvesting and implantation techniques. The success of composite no-touch SVG to LITA seems to be similar to that of the LITA and right internal thoracic artery composite, perhaps because of appropriate negative remodeling; however, given the lack of strong evidence in this area, this technique should still be used as a bailout rather than routinely. In general, however, the evidence for SVG use is beginning to resurge; there are long-term single-center data ( 8.5 years) that show the no-touch minimal manipulation to carry superior patency rates to conventional harvesting ${ }^{9}$; the results from a multicenter study will be published next year. ${ }^{10}$ In context of the current changing landscape of arterial revascularization, studies such as these provide a humbling reminder that SVGs may still perform well in the right environment.

\section{References}

1. Glineur D, Boodhwani M, Poncelet A, De Kerchove L, Etienne PY, Noirhomme P, et al. Comparison of fractional flow reserve of composite Y-grafts with saphenous vein or right internal thoracic arteries. J Thorac Cardiovasc Surg. 2010;140:639-45.

2. Yuan SM, Shinfeld A, Raanani E. Configurations and classifications of composite arterial grafts in coronary bypass surgery. J Cardiovasc Med (Hagerstown). 2008;9:3-14.
3. Gaudino M, Alessandrini F, Pragliola C, Luciani N, Trani C, Burzotta F, et al. Composite Y internal thoracic artery-saphenous vein grafts: short-term angiographic results and vasoreactive profile. J Thorac Cardiovasc Surg. 2004;127: 1139-44.

4. Kim KB, Hwang HY, Hahn S, Kim JS, Oh SJ. A randomized comparison of the Saphenous Vein Versus Right Internal Thoracic Artery as a Y-Composite Graft (SAVE RITA) trial: one-year angiographic results and mid-term clinical outcomes. J Thorac Cardiovasc Surg. 2014;148:901-7; discussion 907-8.

5. Hwang HY, Koo BK, Oh SJ, Kim KB. Morphologic changes of the saphenous vein Y-composite graft based on the left internal thoracic artery: 1-year intravascular ultrasound study. J Thorac Cardiovasc Surg. 2015;149: 487-93.

6. Sabik JF III. Understanding saphenous vein graft patency. Circulation. 2011;124 273-5.

7. Sabik JF III, Lytle BW, Blackstone EH, Khan M, Houghtaling PL, Cosgrove DM. Does competitive flow reduce internal thoracic artery graft patency? Ann Thorac Surg. 2003;76:1490-6; discussion 1497.

8. Bicknell CD, Subramanian A, Wolfe JH. Coronary subclavian steal syndrome. Eur J Vasc Endovasc Surg. 2004;27:220-1.

9. Souza DS, Johansson B, Bojö L, Karlsson R, Geijer H, Filbey D, et al. Harvesting the saphenous vein with surrounding tissue for CABG provides long-term graft patency comparable to the left internal thoracic artery: results of a randomized longitudinal trial. J Thorac Cardiovasc Surg. 2006; 132:373-8.

10. Improving the Results of Heart Bypass Surgery Using New Approaches to Surgery and Medication (SUPERIORSVG). ClinicalTrials.gov Identifier: NCT01047449. Bethesda, MD: National Institutes of Health; 2010-2014. Available at: http://www.clinicaltrials.gov/show/NCT01047449. Accessed November 10, 2014. 